\title{
Elite empresarial e elite econômica: o estudo dos empresários
}

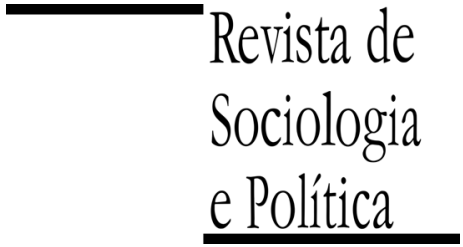

DOI 10.1590/1678-987314225204

\section{Paulo Roberto Neves Costa}

\begin{abstract}
RESUMO
Os objetivos do artigo são verificar como a questão da elite se apresenta na literatura sobre empresariado no Brasil e contribuir para a construção de uma estratégia de análise que se paute por essa questão no estudo dos empresários. A análise dos estudos que tratam do empresariado como elite indica a existência de algumas lacunas e imprecisões. O uso da expressão "elite" nem sempre vem acompanhado do desenvolvimento de suas implicações teóricas e metodológicas. E os trabalhos sobre o empresariado que recorrem a métodos de estudo de elites tendem a associá-los, de forma precária, ao tratamento de outras questões, como a da classe. Nesse sentido, propomos a distinção entre elite empresarial, os dirigentes das entidades de representação do empresariado, e elite econômica, os dirigentes das grandes empresas. Pretendemos contribuir tanto para uma maior precisão das categorias analíticas, quanto para a construção de métodos e hipóteses de trabalho mais eficazes no estudo dos empresários. Ao mesmo tempo, propomos que as particularidades e semelhanças desses dois grupos que compõem a elite do empresariado sejam tratadas, sobretudo, mas não de forma exclusiva ou isolada, a partir da questão da política e das instituições políticas, em particular seus valores e suas formas de ação política.
\end{abstract}

PALAVRAS-CHAVE: empresários; empresariado; elites; elite econômica; elite empresarial.

Recebido em 17 de Fevereiro de 2014. Aprovado em 30 de Outubro de 2014.

\section{Introdução ${ }^{1}$}

\footnotetext{
1 Uma versão inicial deste artigo foi apresentada forma de comunicação Colóquio Elites em diferentes escalas, organizado pelo Núcleo de Pesquisa em Sociologia Política Brasileira da UFPR, em 2013, e faz parte das atividades relativas à Bolsa de Produtividade do $\mathrm{CNPq}$, ao qual expressamos nossos agradecimentos. Agradecemos também às contribuições dos pareceristas anônimos que avaliaram este artigo.

2 Voltaremos a esta questão mais adiante.
}

$\mathrm{O}$ estudo do empresariado por si só remete a um arranjo complexo e diversificado de questões teóricas, metodológicas e históricas que seriam suficientes para um extenso debate. Exatamente em função disso e da diversidade de expressões e conceitos utilizados pela literatura, de um modo geral, usaremos a expressão empresariado simplesmente para nos referirmos ao conjunto diversificado dos proprietários e controladores de empresas, sem, portanto, nenhuma conotação teórica ou metodológica mais profunda ${ }^{2}$.

O objetivo deste artigo é fazer uma revisão bibliográfica e apresentar algumas proposições relativas à análise do empresariado como elite. Para tal revisão não partimos de um dado conceito de elite, por entendermos que se trata de uma questão teórica que é resolvida, de forma mais ou menos rigorosa, pelos próprios estudos. Desta forma, procuramos verificar na literatura voltada para os empresários, de um lado, o uso da expressão elite e, de outro, a utilização de metodologias características de estudos de elite.

Aparentemente, a inserção da questão da elite tornaria esse arranjo de questões ainda mais complexo. Entretanto, ainda que isso seja verdade, uma breve passagem pela literatura mostra que os estudos pioneiros, mais propriamente sociológicos, sobre o empresariado no Brasil tiveram como objeto e como problema metodológico os empresários como uma elite. Referimo-nos aos trabalhos publicados entre meados dos anos 1960 e meados dos anos 1970 por Fernando Henrique Cardoso (1964; 1967), Luciano Martins (1968) e Luiz Carlos Bresser-Pereira (1974). A este grupo poderíamos também acrescentar o trabalho de Renato Boschi (1977). Tais autores se debruçaram sobre questões como as características, a origem social, as capacidades políticas e as idéias de 
${ }^{3}$ Uma versão revisada deste trabalho de Leopoldi foi publicada no Brasil em 2000 (Leopoldi 2000).

${ }^{4}$ Fizemos um primeiro enfrentamento destas questões teóricas em Costa (2012a).

5 Aqui estamos nos referindo à pesquisa International Management Studies, da qual fazemos parte. Ver Pohlmann e Valarini (2013).

${ }^{6}$ Ver Costa $(2007 ; 2012 b)$; Costa e Engler (2008) e Costa, Roks e Santos (2012). Ver Pohlmann e Valarini (2013), além do texto que está publicado neste dossiê. um grupo reduzido e específico, os altos dirigentes de grandes indústrias. E, em torno deste objeto, por vezes utilizaram a expressão elite, mas, sobretudo, enfrentaram questões típicas de estudos de elites.

Outros estudos posteriores sobre o empresariado como, por exemplo, os de Eli Diniz (1978), Angela Maria de Castro Gomes (1979) e Maria Antonieta Leopoldi $(1984)^{3}$, tenderam a voltar-se mais para as suas entidades de representação, também predominantemente da indústria. Entretanto, tais trabalhos não tinham como objetivo central o estudo de elites, mesmo que tenham usado a expressão elites, como ocorreu com os estudos pioneiros. Nos trabalhos de Diniz, Gomes e Leopoldi o uso das expressões "elite empresarial", "elite industrial" ou "elite econômica" se revestem de uma natureza mais propriamente descritiva, ou seja, para se referir aos dirigentes de grandes empresas e ou de importantes entidades de representação. Como veremos adiante, ainda que em termos do objeto isso possa coincidir com os conceitos que aqui estamos propondo, resta a questão metodológica, ou seja, como esse grupo é localizado e analisado.

Em suma, este artigo aborda as formas como a análise de elites esteve presente nos estudos sobre o empresariado no Brasil e como podemos disso retirar elementos importantes para novos e eficazes estudos que utilizem tal análise. Nesse percurso, surgiram questões de natureza teórica e metodológica. As primeiras são fundamentais, mas não serão desenvolvidas, mas apenas brevemente levantadas ${ }^{4}$. Nosso objetivo específico é chamar a atenção para os ganhos analíticos e sugerir modos de resolver alguns problemas metodológicos típicos, embora não exclusivos, do estudo do empresariado como elite e, desta forma, mais do que definir conceitos ou revisar criticamente a vasta literatura sobre o assunto, pretendemos verificar como este problema de análise se coloca em alguns trabalhos importantes e apresentar contribuições para uma abordagem e um procedimento metodológico mais eficazes no estudo do empresariado.

Faremo-lo a partir de duas frentes que, por sua vez, implicam duas noções distintas: a de elite econômica e a de elite empresarial. A primeira toma por referência, de um lado, os estudos pioneiros acima mencionados e, de outro, uma frente de pesquisa sobre a elite econômica no Brasil em perspectiva comparada ${ }^{5}$. Em relação a essa frente, o conceito de elite econômica remete aos proprietários e altos dirigentes das empresas, ou seja, aqueles que possuem e/ou administram grande volume de capital e organizações empresariais complexas. A segunda será aqui representada pelos trabalhos de Diniz (1978) e Boschi (1977), e também de algumas de nossas experiências de pesquisa ${ }^{6}$. Nessa frente, o conceito de elite empresarial vai remeter aos dirigentes de entidades de representação. Como veremos, o uso das duas expressões procede, pois remetem a objetos e problemas distintos, embora, elas possam ser fundidas em uma mesma agenda de pesquisa, dado que mais importante é o problema a partir do qual se pretende construir a análise.

O problema central aqui considerado é mais propriamente de natureza metodológica: como alguns dos principais estudos sobre o empresariado brasileiro enfrentaram o desafio de estudá-lo como uma elite, independentemente da fundamentação teórica e do uso dessa expressão, e quais aprendizados podem ser retirados dessas experiências de análise, visando especificamente o incremento dos estudos sobre o empresariado. No próximo item, trataremos dos estudos sobre a elite econômica e no seguinte sobre a elite empresarial. Por fim, trataremos do estudo dos empresários como elite e faremos nossas considerações finais. 


\section{Os estudos sobre a elite econômica}

Fernando Henrique Cardoso analisou a "participação dos empreendedores industriais no desenvolvimento econômico do Brasil" e a situação do empresariado a partir das conseqüências das transformações na sociedade capitalista sobre as "funções empresariais". A pesquisa sobre os dirigentes de empresas industriais foi realizada entre julho de 1961 e outubro de 1962 e envolveu industriais de São Paulo, Blumenau, Belo Horizonte, Recife e Salvador. Utilizou-se também o resultado de um survey realizado junto aos dirigentes de empresas da grande São Paulo, envolvendo a aplicação de questionários a 288 empresas com mais de 500 empregados (Cardoso 1964).

Luciano Martins, em seu estudo da "burguesia nacional" e da "formação histórica e do comportamento social do empresário industrial brasileiro", realizou uma pesquisa junto aos empresários industriais em meados dos anos 1960 e tratou de questões sobre a reorientação do modelo de desenvolvimento posterior a 1964, através de questionário submetido aos dirigentes dos 50 maiores grupos industriais do Rio de Janeiro e de São Paulo (Martins 1968, p. 26). Ainda que a pesquisa tenha se voltado para os grandes e médios industriais, estes últimos foram considerados apenas quando adicionavam algo às conclusões tiradas a partir dos primeiros. Martins (idem) levantou também informações sobre a ocupação dos pais e avós dos grandes industriais.

Luiz Carlos Bresser-Pereira, para estudar os "empresários industriais e administradores" ou o papel dos "empresários industriais brasileiros" na industrialização e no desenvolvimento econômico e político do Brasil, entrevistou diretores ativos das empresas nacionais e estrangeiras com mais de 249 empregados, localizadas na Grande São Paulo. O autor volta-se para a questão das origens sociais, mas o questionário utilizado mobiliza também variáveis relativas a carreira, cargo ocupado, redes pessoais no âmbito profissional, cultura administrativa, projetos e atividades relacionadas aos filhos, profissão dos pais e avós e situação econômica da família quando da infância e da adolescência (Bresser-Pereira 1974).

Por sua vez, Renato Boschi baseia sua obra em pesquisa que se caracterizou por entrevistas de natureza não estruturada com dirigentes industriais como forma de obter um clima mais informal e favorável à obtenção de informações. A amostra foi criada a partir das indicações feitas pelos próprios entrevistados e se concentraram em São Paulo, entre setembro de 1975 e agosto de 1976. Isso foi completado com a análise de uma das principais associações da indústria, "[...] que compreendia o grosso dos interesses de um segmento substancial da elite empresarial", a Associação Brasileira da Infraestrutura e Indústrias de Base (ABDIB), como forma de "qualificar a hipótese geral", dada a impossibilidade, segundo Boschi, de um teste empírico rigoroso (Boschi 1979, p. 9).

Por último, a pesquisa International Management Studies (IMS), sediada no Instituto Max Weber de Sociologia da Universidade de Heidelberg, Alemanha. Tal pesquisa contempla países como Alemanha, Coréia do Sul, Japão,China, Argentina e Brasil, e especula sobre a existência de um novo espírito do capitalismo no contexto da internacionalização das carreiras e da globalização. A IMS busca analisar a visão gerencial e as percepções dos CEOs das 100 maiores empresas industriais em diversos países. Em linhas gerais, as variáveis mobilizadas são: origem social, educação e qualificação, carreira, redes de contatos e valores relativos à ética, religião, gerenciamento da empresa e

${ }^{7} \mathrm{O}$ questionário utilizado gira em torno dos seguintes fatores: Biografia; Organização do política ${ }^{7}$. No Brasil, o objetivo é, portanto, analisar as características coletivas dos altos dirigentes das maiores empresas industriais, considerados como membros da elite econômica brasileira, no contexto atual ${ }^{8}$. 
trabalho e produção; Moral e política; Participação e relações com os funcionários; Orientação da ação e Cultura de gerenciamento; Estilo de vida. O questionário foi aplicado também aos altos dirigentes do segundo escalão e a ex-altos dirigentes, permitindo problematizar a questão da reprodução e do recrutamento.

${ }^{8} \mathrm{Na}$ versão brasileira desta pesquisa foi introduzido um bloco de questões sobre a política e as instituições políticas.

${ }^{9}$ As entrevistas são realizadas por diferentes jornalistas e não seguem um padrão de questões e perguntas. Além disso, estas publicações contemplam todos os setores da atividade econômica, enquanto que a pesquisa IMS dedica-se aos industriais.

${ }^{10}$ Um primeiro esboço desta questão da relação entre análise de elite e análise de classe está em Costa (2012a). Esta discussão foi desenvolvida e sistematizada em Costa (2013).

${ }^{11}$ Por exemplo, Cardoso (1964) chama a atenção para o fato de que as "elites dirigentes da economia" tornaram-se também "elites
Tivemos a oportunidade de confrontar algumas das variáveis usadas pela pesquisa IMS com o conteúdo de entrevistas com os dirigentes das empresas campeãs do levantamento de 2010 da publicação Valor 1000 e da edição especial "Empreendedores do ano" de IstoÉ Dinheiro deste mesmo ano (Costa \& Romko 2011). O objetivo era fazer um levantamento das fontes de informação disponíveis na imprensa especializada na área de Economia que pudessem ser úteis para a realização de uma pesquisa sobre a elite econômica brasileira nos dias de hoje.

Nesse breve exercício de comparação, verificamos que, em primeiro lugar, as informações apresentadas por essas publicações a respeito dos membros da elite econômica brasileira mostram que elas se apresentam como fontes muito úteis para a composição do objeto de pesquisa, ou seja, a localização dos dirigentes das maiores. Em segundo lugar, apesar da ausência de informações sobre algumas variáveis importantes devido aos problemas de ordem metodológica ${ }^{9}$, no caso, sobre background familiar, carreira e estilo de vida, existem algumas coincidências dos assuntos presentes nas entrevistas com aqueles contidos no questionário utilizado pela pesquisa $I M S$ e dos estudos pioneiros sobre o empresariado no Brasil.

Enfim, podemos observar a utilidade desses levantamentos realizados pelas publicações da área de Economia para a composição do objeto de uma pesquisa, ou mesmo para obter algumas informações iniciais sobre a elite econômica no Brasil. Isso se deve, de um lado, aos critérios utilizados para a composição do grupo, no caso, as maiores empresas. E de outro, pela indicação de nomes dos altos dirigentes das empresas, os quais poderiam ser entrevistados a partir de um questionário padronizado e sociologicamente orientado. Entretanto, as vantagens desta fonte param por ai, dados os limites, a inconstância e a imprecisão dos procedimentos metodológicos utilizados.

Em suma, dos estudos sobre a elite econômica, em primeiro lugar, destacase a importância da análise de elites na constituição do campo de pesquisa sobre o empresariado no Brasil, dada a relevância, e não apenas o pioneirismo, dos trabalhos de Fernando Henrique Cardoso, Luciano Martins, Luiz Carlos Bresser-Pereira e Renato Boschi. Em segundo lugar, nota-se que, nesses trabalhos o estudo da elite econômica se caracteriza exatamente pela forma de analisar a classe, ou seja, o objetivo é estudar a "burguesia", mas a forma de fazê-lo é analisando a elite econômica ${ }^{10}$.

Em terceiro lugar, estas pesquisas voltaram-se prioritariamente para os dirigentes de empresa, a elite econômica. Mas essa é uma delimitação menos relevante, se considerarmos que uma pesquisa muito abrangente se tornaria inviável, ainda mais nas condições e com os recursos que esses estudiosos possuíam quando da realização de suas pesquisas e que não são muito diferentes nas pesquisas atuais. Por último, podemos destacar a importância das variáveis que foram utilizadas por estes estudos, o que pode ser atestado inclusive pela presença das mesmas variáveis na pesquisa $I M S$, o que permite também uma comparação de ordem cronológica, dado que os dados obtidos por esta pesquisa sobre a elite econômica brasileira nos dias de hoje podem ser comparados com aqueles obtidos pelas pesquisas realizadas nos anos de 1960 e 1970.

Parece-nos mais relevante ressaltar que, de um lado, Cardoso (1964) e Martins (1968) voltaram-se mais para as questões relacionadas ao gerenciamento e a análise da economia, e de outro, Bresser-Pereira (1974) voltou-se para a questão da origem social. Ou seja, há a ausência, de certa forma constatada pelos próprios autores ${ }^{11}$, de uma discussão mais profunda sobre a questão da política e das instituições relativas ao processo decisório, em especial das políticas econômicas. Neste aspecto, os trabalhos de Martins (1968) e Boschi (1979) se destacam. O primeiro, ao colocar a questão dos conflitos internos e 
políticas". Ou seja, o êxito da própria empresa exigia que se ultrapassasse o âmbito restrito dos negócios empresarias e se interferisse no sistema de poder, disputando espaço com os novos grupos gerados pela própria dinâmica da produção moderna, proprietários ou não proprietários. externos à "burguesia", a avaliação sobre o poder dos empresários e de outros agentes sociais, a importância política das instituições e até a intensidade dos contatos políticos. E o segundo, por considerar a forma como os empresários pensavam a questão do regime político em um momento de transformação das instituições políticas.

Em relação à pesquisa $I M S$ destacamos o fato de que, embora restrita à elite econômica e mais especificamente da indústria, ela contempla questões de grande amplitude sociológica, ou seja, que dizem respeito a várias das dimensões da existência do dirigente de empresa, inclusive procurando apreender, através da biografia do indivíduo, aspectos da formação e da reprodução desta elite. Além disso, como vimos acima, essa pesquisa introduz outro ganho analítico importante, que é a forma como se utiliza o material de imprensa como espaço de expressão e de formação da opinião dos membros dessa elite. Outro aspecto importante da pesquisa é retomar algumas das questões que foram levantadas nos trabalhos pioneiros, como, por exemplo, a visão acerca da empresa, do mercado e também a ocupação dos antepassados dos industriais, como forma de apreender as características do recrutamento.

\section{Os estudos sobre a elite empresarial}

${ }^{12}$ Em relação a este último aspecto, os autores partiram dos nomes que apareceram no fórum da Gazeta Mercantil entre 1979 e 1989. Foram usados também os dados do Grupo de Análise de Conjuntura do Instituto de Pesquisa Social da Escola de Sociologia e Política de São Paulo, a partir dos quais foram levantados os nomes dos empresários que mais apareceram na grande imprensa.
${ }^{13}$ Ver Costa (2007; 2012b); Costa e Engler (2008); Costa, Roks \& Santos (2012).
Entre os diversos trabalhos de Eli Diniz e Renato Boschi, encontramos uma análise da representação de interesses empresariais no Brasil a partir dos anos 1990 (Diniz \& Boschi 2004). Em sua pesquisa, os autores utilizaram questionários e também entrevistas em profundidade com os dirigentes de entidade de representação e com as "lideranças do mundo empresarial". Os problemas tratados giram em torno dos "valores e percepções" e da "visão das lideranças empresariais" acerca das mudanças ocorridas naquele momento. Diniz e Boschi ressalvam que nem todos os dirigentes de entidade são empresários, pois, como é comum, podem ser profissionais contratados pelas entidades. Quanto às "lideranças empresariais", o critério adotado para localização dos componentes desse grupo seria mais próximo do reputacional, dado que parte do "critério de visibilidade pública", o que resultou em sete nomes $(\text { idem })^{12}$.

Outro trabalho que ilustra a análise da elite empresarial é o de Payne (1995), que usa as expressões "business leaders" e "business elite". Em sua pesquisa, os questionários foram aplicados entre 1986 e 1988, com 155 empresários entrevistados. Assim como Diniz e Boschi (2004), Payne levou em conta principalmente os presidentes de entidades e alguns empresários industriais paulistas, que foram importantes no período entre 1964 e 1988, que tinham destaque na imprensa e que eram citados nos documentos das entidades e na literatura. A pesquisa foi feita também com os proprietários de terra, representados pela União Democrática Ruralista (UDR). O critério para caracterizar a importância deste grupo foi, de um lado, o poder econômico e, de outro, as conexões com os decisores da política econômica. O questionário girou em torno do background social dos empresários e das características das firmas, com questões abertas sobre as relações de trabalho, os debates que se davam no Congresso Nacional, o governo (Presidente da República) e outros temas políticos (Payne 1995).

Por sua vez, nossas pesquisas recentes, se pautaram pela tentativa de definir com precisão o objeto, no caso, os dirigentes de entidades empresariais de diversos setores e amplitude de ação (nacional ou estadual) ${ }^{13}$. Em alguns casos, durante a aplicação dos questionários, da mesma forma que ocorreu na pesquisa de Diniz e Boschi (2004), também tivemos a presença de profissionais ou técnicos entre os entrevistados, embora a grande maioria tenha sido de presidentes e alguns diretores. 
${ }^{14}$ Além de dados sobre as trajetórias social, educacional e profissional, os problemas a partir dos quais foi tratada a questão da democracia foram: o grau de adesão, a concepção de democracia, a avaliação sobre os possíveis obstáculos à democracia, o autoposicionamento no espectro político-ideológico e a opinião sobre algumas políticas públicas (Costa \& Engler 2008)
Em um primeiro momento, o objetivo era verificar quais seriam as concepções sobre a democracia, as instituições políticas, a necessidade e o processo de uma reforma política e o possível impacto do comportamento do empresariado em relação ao funcionamento do regime político democrático. Embora neste momento ainda não se colocasse a questão da análise de elite, e mesmo que estivéssemos considerando aquilo que posteriormente viríamos a chamar de elite empresarial, o problema em torno do qual a pesquisa foi feita não foi a relação entre empresariado e economia ou política econômica, mas sim a política e as instituições democráticas (Costa 2007).

Em um segundo momento, surge a questão e a análise de elite e o uso da noção de elite empresarial. Nossa preocupação era não apenas com a circunscrição do objeto, mas também com a forma como eles seriam considerados, ou seja, a partir do seu papel no exercício da representação institucionalizada dos interesses de seus pares e dos valores relacionados à política, às instituições políticas e à democracia. Enfim, o critério era mais do que simplesmente posicional, dado que isso era apenas para localizar os indivíduos, e sim o exercício da política, o que fazia dessa elite parte das elites políticas como um todo. As questões priorizadas foram, de um lado, a homogeneidade da elite estudada, tratada a partir do recrutamento e da trajetória política, entendida como a carreira política percorrida antes e durante o exercício da presidência da entidade, e, de outro, a coesão, verificada a partir dos valores políticos relacionados à democracia (Costa \& Engler 2008) ${ }^{14}$.

Posteriormente, voltamos a considerar a posição dos dirigentes de entidade de representação sobre a democracia, mas com duas alterações: introduzimos no questionário um pedido de justificativa das respostas, ou melhor, dos posicionamentos, e reforçamos as questões relacionadas aos padrões de ação política (Costa 2012b).

Por fim, em um estudo sobre o caso do Paraná, procuramos articular um conjunto de problemas e variáveis, que vão desde a origem social, a trajetória educacional e a experiência em outras organizações, passando pelas opiniões frente à democracia e às instituições em funcionamento no Brasil de nossos dias, até os padrões de ação política, mantendo a prática de pedir justificativas para os posicionamentos expressos pelos entrevistados (Costa, Roks \& Santos 2012).

Enfim, a respeito dos estudos sobre a elite empresarial podemos destacar a sugestão de Diniz e Boschi (2004) de utilização do método reputacional no processo de localização e composição do objeto, ou seja, daqueles que teriam maior reconhecimento por parte de seus pares. O que se deve evitar é tomar tal reputação, principalmente quando ela vem de dimensões externas ao mundo empresarial, por exemplo, a imprensa, como sinônimo de capacidade política ou de representação. Os trabalhos desses autores, assim como o de Payne, também destacam a importância de se analisar a relação com os centros de poder, ou seja, com o processo decisório, ainda que tenham se restringido à política econômica. Mas Payne (1995) acrescenta questões que estavam presentes nos estudos pioneiros, por exemplo, Bresser-Pereira, tais como background social e relações de trabalho, e outras sobre as instituições políticas.

Nos trabalhos de Diniz e Boschi (2004) e Payne (1995) o objeto se aproxima do que estamos considerando como elite empresarial e o método mobiliza ao menos uma das variáveis que achamos importante, os valores políticos. E levantam também o problema da definição dos critérios de localização e seleção dos nomes que comporiam o universo a partir do qual se busca constituir o objeto. Se há vantagens nos critérios de seleção usados pelos autores, pode também haver problemas pois, de um lado, há um aspecto institucional, ou seja, o vínculo a uma entidade, e de outro, os critérios usados pela mídia. 
${ }^{15}$ Sobre isso, ver Diniz e Boschi (2004, p. 165).
Isso remete a outro problema, comum aos estudos de elites: a dificuldade de obter um $\mathrm{N}$ que permita a utilização de métodos qualitativos. Outro problema é que os autores usam os critérios de visibilidade pública como forma de não apenas localizar como também analisar e caracterizar esta "liderança", e tirar conclusões sobre o processo de sua constituição e composição e, inclusive, de "renovação" 15 . Não se trata de desqualificar esse critério ou os trabalhos citados, mas sim de considerar que, como os próprios autores indicam e como constatamos no item anterior, tais fontes estão sujeitas às flutuações metodológicas ${ }^{16}$. Por último, falta uma articulação maior com a análise da ação, o que procuramos, apenas parcialmente, contemplar em nossas pesquisas (Costa 2012a; 2012b; Costa, Roks \& Santos 2012). Voltaremos a esta questão mais adiante.

\section{O estudo dos empresários como elite}

${ }^{16}$ Sobre isso, ver a nota 2 do Capítulo 5 (Diniz \& Boschi 2004). Como vimos acima, outro exemplo desse mesmo problema são os materiais de imprensa como as entrevistas contidas nas edições anuais da Valor 1000 e de edições especiais, como

"Empreendedores do ano" da IstoÉ Dinheiro. Porém, este problema também não é exclusivo da imprensa, como mostra o livro Elites empresariais paulistas (Escola de Ciências Sociais 2011).

${ }^{17}$ As articulações e as sobreposições entre estas duas frentes podem ser exploradas por diversas questões e metodologias, como, por exemplo, a de análise de redes, usadas em trabalhos como o de Minella (2007) e Toledo (2009).
Em primeiro lugar, devemos considerar que os empresários são contemplados em estudos clássicos sobre o conjunto da elite política brasileira e também podem ser considerados como parte de elites políticas específicas, como as parlamentares. Entretanto, nosso objetivo é tratar mais particularmente das diferenças e, sobretudo das articulações entre estas duas frentes da elite dos empresários aqui consideradas, a elite econômica e a elite empresarial.

Em relação à presença dos empresários na elite política brasileira, podemos mencionar os trabalhos de Love (1982) e Love e Barickman (2006). Há também os importantes estudos Dreifuss $(1981 ; 1989)$ sobre os empresários como parte da "elite orgânica". Em outros trabalhos, tivemos a oportunidade de estudar os senadores-empresários, ou seja, os membros do Senado brasileiro que exerciam atividades empresariais antes do mandato, dialogando com trabalhos importantes sobre a elite parlamentar (Costa, Costa \& Nunes, 2014), e também a questão da relação entre os empresários e as "elites estatais" (Perissinotto et al., 2014).

Embora apareçam de forma articulada nos estudos acima mencionados, devemos considerar que se trata de competências e responsabilidades distintas e que se dão em duas organizações igualmente distintas: a empresa e entidade de representação. Isso implica pensar também nas particularidades da atuação das burocracias destes dois tipos de organizações com as quais cada uma destas frentes se relaciona, o que se coloca como uma importante agenda de pesquisa. No caso da elite empresarial, os estudos acima mencionados indicam que a presença de técnicos que atuam nas entidades, assim como de gerentes do segundo escalão das empresas, não se coloca como um problema de ordem metodológica. Sabemos que nestas duas frentes, assim como em outros tipos de elite, os dirigentes se resguardam de uma série de assessores no auxílio de suas funções.

E não estamos aqui problematizando a capacidade de influência de cada uma destas frentes, nem analisando os possíveis conflitos e articulações entre elas, o que se coloca como outra interessante agenda de pesquisa ${ }^{17}$. O que pretendemos é enfatizar a importância de distinguir e reconhecer as particularidades destes dois grupos nas análises sobre o empresariado e deste enquanto elite. Não se trata de duas atividades separadas, mas de duas frentes do processo de formação do empresariado como elite, e algo que parece ser não só algo peculiar como também exclusivo aos empresários.

A despeito dos primeiros estudos sociológicos sobre o empresariado terem se caracterizado como estudos de uma elite econômica, ainda são poucos os trabalhos sobre esse tema construídos a partir das questões teóricas e metodológicas da análise de elites, a despeito do uso da expressão "elite". Além disso, tanto os trabalhos pioneiros quantos os mais recentes tenderam a limitar-se aos 
${ }_{18}$ Apenas para exemplificar, o caso brasileiro já mostra a existência de duas sub-dimensões da elite empresarial, aquela das entidades sindicais e a das entidades associativas. A nosso ver, este aspecto institucional não pode ser reduzido a uma explicação exclusivamente histórica e institucional, mas deve contemplar a dinâmica dos conflitos de interesses no interior do empresariado e deste com o Estado e a sociedade. industriais, em especial paulistas. Nesse sentido, algumas observações de ordem metodológica, decorrentes dos comentários acima, podem contribuir para o desenvolvimento dessa agenda de pesquisa e interpretação sociológica do empresariado.

Começando pela questão da definição ou da forma de caracterizar a elite do empresariado, em primeiro lugar, podemos considerar distinção acima mencionada: a elite econômica, pensada a partir do exercício de poder econômico relevante, no caso, de gerenciamento de grandes empresas e a elite empresarial, aquela mais afeita ao exercício da política, a direção de entidades de representação. Em geral, a condição de elite se caracteriza por alguma diferença em relação ao coletivo mais amplo, à população ou até mesmo à classe.

No caso do empresariado, há uma diferenciação possível no interior da própria elite, ou duas dimensões ou frentes desta mesma: de um lado, aquela relacionada às posições de destaque no exercício da função fundamental que caracteriza o grupo, ou seja, a atividade capitalista; e de outro, em comum com outros tipos de elite, o exercício da atividade de representação política, seja frente aos seus pares, seja frente às instituições políticas e ao processo decisório.

Entretanto, devemos considerar que não se trata de atividades exclusivas de cada um desses subgrupos, ou seja, os membros da elite econômica podem e frequentemente lidam com as questões políticas, e os membros da elite empresarial não deixam de ser empresários, mesmo que não sejam parte da elite econômica. Trata-se de duas competências e trajetórias específicas, cujas distinções podem ser pensadas a partir desde conceitos fundamentais como a questão das vocações propostas por Weber, até particularidades institucionais relativas àquilo que se definiu como objeto de estudo ${ }^{18}$.

Além disso, podemos acrescentar a particularidade das grandes cooperativas empresariais, cujos líderes não são propriamente empresários no sentido de exclusivamente gestores e/ou proprietários de grande volume de capital, nem são especificamente dirigentes de entidades de representação. Entretanto, gerenciam de forma empresarial cooperativas que disputam e ocupam posições importantes no mercado, portanto, são gerenciadas como e possuem características de grandes empresas e, além disso, ou em função disso, exercem a representação dos interesses da cooperativa, na sua dimensão empresarial, e dos cooperados, na sua dimensão cooperativista. Isso sinaliza outras frentes de pesquisa que ultrapassam, mas não se contrapõem ao que aqui se propõe. Afinal, a idéia não é simplesmente apresentar conceitos, mas colaborar para a qualificação da abordagem e da criação de boas questões e hipóteses de trabalho.

Daí, se os estudos podem se voltar para um ou outro grupo, se coloca também a possibilidade de considerar os grupos, utilizando ou não uma única expressão. Sendo assim, a fusão das duas expressões ou a necessidade de escolher uma ou outra não se coloca como a questão mais importante, dado que a importância da distinção diz respeito apenas a precisão em relação a qual subgrupo o estudo se dedica e ao reconhecimento de suas particularidades. Da mesma forma que para tratarmos da elite parlamentar seria necessário especificar, entre outras coisas, a qual dos níveis do Legislativo se está referindo (vereadores, deputados estaduais, deputados federais e senadores), no caso do empresariado é necessário distinguir com precisão se estamos falando da elite econômica ou empresarial. Isso não descarta a possibilidade, ou até a necessidade, também possível no exemplo dos parlamentares, de serem consideradas mais de uma dimensão. Como mostram os trabalhos acima comentados, trata-se de duas dimensões de um mesmo objeto e de uma mesma grande questão sociológica, que a literatura sobre o caso brasileiro por vezes aproxima ou separa. 
${ }^{19}$ Por exemplo, é possível perguntar sobre política ou sobre gestão empresarial tanto a membros da elite econômica como da elite empresarial, mas perguntar para um gerente de empresa sobre a gestão de uma entidade de representação, ou seja, de algo com o qual ele não está familiarizado, pode gerar distorções.
E se o objetivo for considerar o conjunto da elite do empresariado, ou seja, as suas duas dimensões, a escolha da expressão seria menos importante do que a definição com precisão da questão e do objeto a partir da qual isso seria feito, bem como a consideração dos eventuais ganhos advindos de comparações entre aquelas dimensões. Essa questão certamente seria escolhida a partir de um elenco de tantas outras, que vão da origem social aos valores e atitudes, passando pelas formas de ação. Assim, a homogeneidade e a coerência metodológica seriam dadas pela questão sociológica.

Podemos usar como exemplo os próprios estudos pioneiros, que tomaram a elite econômica do empresariado como forma de estudar a classe, ou, como era mais comum, a "burguesia". Enfim, a questão da classe poderia unificar teórica e metodologicamente as duas dimensões. Entretanto, não foi isso que aqueles estudos fizeram, dado que se voltaram apenas para a elite econômica e para um conjunto específico de questões. Embora essa seja outra discussão (parte das questões teóricas relativas à análise do empresariado que aqui não foram desenvolvidas), entendemos que a análise de elite como uma forma de análise de classe exigiria que se considerasse tanto a elite econômica quanto a empresarial. E também tanto a consideração dos diversos setores empresariais, ou as chamadas frações, como expressões usadas em trabalhos como os de Gomes (1979) e Boschi (1979), quanto também questões de diversas naturezas, da origem social aos valores e padrões de ação política.

Este nível mais amplo de problematização da elite do empresariado não se contrapõe nem se sobrepõe às inúmeras frentes específicas que em geral são desenvolvidas pelos estudos sobre o tema, e se caracteriza mais propriamente como outra agenda de questões. Mas entendemos que o fundamental é a tentativa de articulação entre essas frentes específicas e aquela mais ampla, mesmo que isso só venha a se realizar ao longo do tempo e em função do acúmulo de pesquisas e reflexões, para o que este artigo pretende contribuir.

Resolvida a questão da caracterização sociológica, outro problema que se coloca é o da localização dos indivíduos que comporiam a elite. Entendemos que, embora o método posicional seja o mais indicado, o reputacional pode também ser útil, desde que usado com cuidado. Mas o mais importante é definir com precisão o uso que deles se faz e principalmente a preservação de algo que unifique as indicações - por exemplo, a condição de alto dirigente de empresa ou de entidade de representação -, e também a homogeneidade das questões ${ }^{19}$.

Além disso, ainda que seja uma questão que se coloque para todos os tipos de elite, entendemos que há a necessidade de uma análise da ação ou do comportamento das duas frentes da elite do empresariado. Mais do que meramente constatar as coerências e incoerências com outras variáveis, como origem social, trajetórias e valores, isso permitiria verificar como se dá concretamente o enfretamento dos desafios e condições que caracterizam a vida social efetiva dos indivíduos que compõem a elite e as implicações disso sobre a sociedade, a política, a economia, as instituições e a cultura.

Em relação a esse aspecto, podemos adiantar que é necessário abandonar ou usar com muito cuidado a idéia de representação como correspondência autêntica daquilo que seria o coletivo, seus interesses, seus valores e comportamentos. Mais interessante é considerar a representação não nesse sentido pretensamente empírico, mas sim em um sentido sociológico. Ou seja, de que a elite, por ser um conceito, e não o próprio objeto, expressa as características históricas concretas através das quais os componentes do coletivo enfrentam os desafios associados às suas condições sociais concretas, e do coletivo do qual a elite decorre. Portanto, somente nesse sentido a elite representa o grupo ou classe social, ou seja, por serem aqueles que foram selecionados como os que se 
20 Sobre esta questão, ver Costa (2012a).

\section{Conclusões}

Paulo Roberto Neves Costa (paulocostaufpr@gmail.com) é Doutor em Ciências Sociais pela Universidade Estadual de Campinas (Unicamp), professor de Ciência Política da Universidade Federal do Paraná (UFPR) e coordenador do Núcleo de Pesquisa em Sociologia Política Brasileira (NUSP) na mesma universidade.

\section{Referências}

Boschi, R. 1979. Elites industriais e democracia. Rio de Janeiro, Graal.

Bresser-Pereira, L.C.1974.Empresáriose administradores no Brasil. São Paulo: Brasiliense.

Cardoso, F.H. 1964. Empresário industrial e desenvolvimento econômico no Brasil. São Paulo: Difel.

1967. Las elites empresariales en America Latina. In S.M. Lipset; A.E. Solaris, eds. Elites y desarrollo en America Latina. Buenos Aires: Paidós.

Costa, P.R.N. 2007. Empresariado, instituições democráticas e reforma política. Revista de Sociologia e Política, 28, pp. 99-116.

. 2012a. A elite empresarial - teoria e método na análise da relação entre empresariado e democracia. In $36^{\circ}$ Encontro anual da ANPOCS. Águas de Lindóia.

2012b. A elite empresarial e as instituições democráticas: cultura política, confiança e padrões de ação política. Opinião Pública, 18(2), pp. 452-469. destacaram no enfrentamento dos desafios, não só econômico, mas também políticos, sociais e culturais, colocados ao coletivo ${ }^{20}$.

Enfim, seguindo as proposições de Max Weber, entendemos que não estamos tratando meramente de um conjunto de dados sociais, políticos, econôempresas e entidades, permitindo verificar, ainda que de uma dada perspectiva, como o capitalismo, em todas as suas dimensões, transformou-se (ou não), de que forma e por quê.

de análise de elites, convém sumarizar os principais aspectos deste procedi(a) início, o próprio conceito de elite. Em seguida, outras se colocam, tais como a da ação coletiva, a da representação política, da cultura política, da classe social e

Em termos dos procedimentos metodológicos, definir com precisão de qual dimensão se está tratando, buscar considerar o maior elenco de problemas de análise possível, ou seja, da origem social aos valores políticos. Nesse ponto, aliás, a busca pelas justificativas também se mostrou de grande utilidade.

Nesse aspecto, os estudos de caso podem ser uma boa saída diante da Martins (1968) como os médios empresários e como o faz a pesquisa IMS com

Nossos argumentos foram no sentido de contribuir não apenas para o estudo do empresariado a partir da análise de elite, mas reforçar a importância dos o o surgimento da análise sociológica do empresariado e da própria Sociologia no Brasil. outras questões das sociedades, seja pelos seus aspectos econômicos, políticos. sociais ou culturais, seja por suas instituições. Enfim, trata-se apenas de manter 
2013. Classe social e elite nos estudos sobre empresariado no Brasil. In $37^{\circ}$ Encontro Anual da Anpocs. Águas de Lindóia.

Costa, P.R.N.; Engler, I.J.F. 2008. Elite empresarial: recrutamento e valores políticos (Paraná, 1995-2005). Opinião Pública, 14(2), pp.486-514.

Costa, P.R.N.; Romko, I.G. 2011. Methodological Notes for the Study of Economic Elite in Brasil. In $5^{\circ}$ Simpósio BrasilAlemanha. Stuttgart.

Costa, P.R.N.; Costa, L.D.; Nunes, W. 2014. Os senadores-empresários: recrutamento, carreira e partidos políticos dos empresários no Senado brasileiro (1986-2010). Revista Brasileira de Ciência Política, 14, pp. $227-253$.

Costa, P.R.N.; Roks, T.J.; Santos, G.O. 2012. Recrutamento, valores e padrões de ação política da elite empresarial. Revista de Sociologia e Política, 20(43), pp. 221-246.

Diniz, E. 1978. Empresário, Estado e capitalismo no Brasil: 1930/1945. Rio de Janeiro: Paz e Terra.

Diniz E.; Boschi, R.R. 2004. Empresários, interesses e mercado. Dilemas do desenvolvimento no Brasil. Belo Horizonte/Rio de Janeiro: Editora da UFMG/Iuperj.

Dreifuss, R.A. 1981. 1964: a conquista do Estado. Petrópolis: Vozes. 1989. O jogo da direita. Petrópolis: Vozes.

Gomes, A.M.C. 1979. Burguesia e trabalho: política e legislação social no Brasil, 1917-1937. Rio de Janeiro, Campus.

Leopoldi, M.A.P. 1984. Industrial Association and Politics in Contemporary Brazil. Oxford. Tese (Doutorado em Ciência Política). University of Oxford.

2000. Política e interesses na industrialização brasileira. As associações industriais, a política econômica e o Estado. Rio de Janeiro: Paz e Terra.

Love, J. 1982. A locomotiva. São Paulo na federação brasileira. Rio de Janeiro: Paz e Terra.

Love, J.; Barickman, B.J. 2006. Elites regionais. In F.M. Heinz, ed. Por outra história das elites. Rio de Janeiro: FGV.

Martins, L. 1968. Industrialização, burguesia nacional e desenvolvimento. Rio de Janeiro: Saga.

Minella, A.C. 2007. Representação de classe do empresariado financeiro na América Latina: a rede transassociativa no ano 2006. Revista de Sociologia e Política, 28, pp. 31-56.

Payne, L.A. 1995. Brazilian Business and the Democratic Transition: new attitudes and influence. In E. Bartell; L.A. Payne, eds. Business and Democracy in Latin America. Pittsburg: University of Pittsburg Press.

Perissinotto, R.; Costa, P.R.N.; Nunes, W; Ilha, A.M. 2014. Elites estatais e industrialização: ensaio de comparação entre Brasil, Argentina e México (1920-1970). Revista de Economia Política, 34(3), pp. 503-519.

Pohlmann, M.; Valarini, E. 2013. Elite econômica no Brasil: discussões acerca da internacionalização da carreira de executivos brasileiros. Revista de Sociologia e Política, 21(47), pp. 39-53.

Toledo, D.G.C. 2009. FIESP: as redes empresariais da elite industrial de São Paulo 1992/2004. São Paulo: Papagaio.

Escola de Ciências Sociais. 2011. Elites empresariais paulistas. Rio de Janeiro: FGV.

\section{ABSTRACT}

This article intends to analyze how the issue of elite is used on the studies on businessmen in Brazil and to contribute to building an effective approach of them as elite. We can find some gaps and inaccuracies on these studies. The use of the term elite is not always accompanied by the development of its theoretical and methodological implications. And some studies that use methods of study of elites for analyze businessmen tend to associate it, precariously, to the treatment of other issues such as the social class. In this sense, we propose a distinction between business elite, the leaders of representative organizations of businessmen, and economic elite, the leaders of big companies. We intend to contribute both to greater accuracy of the analytical categories and for the construction of more effective hypotheses and methods for the study of businessmen. At the same time, we propose that the peculiarities and similarities of these two groups that compose the elite of businessmen is handled primarily, but not exclusively or isolated, from the question of politics and political institutions, in particular their values and ways of political action. 